\title{
Correlation between Quantitative Ultrasonography on Small Muscles of the Foot in Diabetic Peripheral Neuropathy and Electrodiagnostic Study
}

\author{
HANAN E. EL HEFNAWY, M.D.*; HOWAYDA F. ZIDAN, M.D.*; SOAD S. EL MOLA, M.D.**; \\ AMR M. GAMIL, M.D.*** and AGYAD H. ABD EL MONIEM, M.Sc.** \\ The Department of Physical Medicine, Rheumatology \& Rehabilitation, Faculty of Medicine, Ain Shams University, Cairo*, \\ Department of Rheumatology, Physical Medicine \& Rehabilitation** and Department of Radiodiagnosis***, \\ National Institute of Neuro-Motor System, Giza, Egypt
}

\begin{abstract}
Background: DPN is worthy of study as it's a leading cause for disability due to foot ulceration and amputation, gait disturbance, and fall-related injury. That makes the early diagnosis of DPN invaluable.
\end{abstract}

Aim of Study: To assess the correlation between quantitative muscle ultrasonography (US) findings and electrodiagnostic study results in patients with diabetic peripheral neuropathy (DPN). The clinical importance of quantitative muscle US in DPN was also evaluated.

Patients and Methods: Twenty-five patients with DPN and 25 healthy volunteers were recruited. All control and DPN subjects underwent a bilateral peroneal and tibial motor nerve conduction study (NCS) and quantitative muscle US. Ultrasound images of the abductor haullicis $(\mathrm{AH})$ muscle and the extensor digitorum brevis (EDB) muscle were obtained to measure thickness, muscle cross-sectional area (CSA) and echo intensity (EI). Differences in muscle thickness, CSA, and EI between the control and DPN patients' groups were analyzed. Relationships between electrodiagnostic study results and quantitative US parameters were evaluated.

Results: A close relations observed between US findings (EI, CSA and muscle thickness) and NCS neuro-physiological findings indicating that we can use both examinations to detect muscle atrophy, and that US can expect changes in neurophysiologic parameters in diabetics (muscle thickness and CSA were decreased, and EI was increased). The findings in the peroneal nerve were more significant than those in tibial nerve. Comparison between cases and controls regarding quantitative muscle US revealed a statistically insignificant difference in most the parameters, but some parameters showed statistically significant difference. However, there was a clinical importance of the US examination despite the insignificant statistics.

Correspondence to: Dr. Agyad Hashem Abd El Moniem, E-Mail: agyad.hashem.aa@gmail.com
Conclusion: These findings suggest that quantitative muscle ultrasound may be useful for detecting muscle changes in DPN. Further studies are needed to confirm the findings in larger groups of diabetic patients and to evaluate peripheral muscles by using quantitative muscle US in other types of neuropathy and neuromuscular diseases.

Key Words: Diabetic peripheral neuropathy - Quantitative muscle ultrasonography - Echo intensity - Electrodiagnostic study.

\section{Introduction}

ONE of the largest global health-care problems of the $21^{\text {st }}$ century is diabetes. The number of diabetic patients worldwide is predicted to reach a level of 366 million people by 2030 . Diabetes has lots of complications, one of them is diabetic neuropathy which is very common [1].

Diabetic peripheral neuropathy (DPN) is defined as the presence of symptoms and signs of peripheral nerve dysfunction in diabetic patients after the exclusion of other causes that may cause peripheral neuropathy. The peripheral neuropathy manifestations associated with diabetes can be classified into distinct clinical syndromes, symmetrical polyneuropathies versus focal or multifocal neuropathies. The pathological lesions include acute axonal degeneration, some degree of demyelination, loss of myelinated fibers, and small endoneurial blood vessel vasculopathy [2].

DPN is worthy of study as it's a leading cause for disability due to foot ulceration and amputation, gait disturbance, and fall-related injury. That makes the early detection of symptoms of DPN invaluable, as it helps avoid heavy losses as neuropathic foot 
ulcers, possible limb loss, muscles denervation causing muscles weakness and atrophy.

Nerve conduction study (NCS) is the gold standard for assessing muscle denervation in peripheral neuropathy [3]. Unfortunately, NCS can be uncomfortable for patients as the electrical impulse is unfavorable for many patients. Furthermore, patient cooperation is necessary for obtaining correct results during this test [4].

That's why interest in high-resolution ultrasonography (US) is increasing [5].

The musculoskeletal ultrasonography (MSK US) in the other hand is noninvasive and more readily available. US has also the advantage of providing real-time and dynamic information on patients [6]. Musculoskeletal ultrasonography can detect decreased muscle thickness and crosssectional area (CSA), which is apparent in neuromuscular disorders. US can also detect fibrosis and fatty atrophy of muscle [7].

The quality of skeletal muscle can be assessed using (US) imaging [8]. The normal muscle tissue is echogenic, and ultrasound is travelled through the muscle tissue easily, but ultrasound is reflected from the fibrous tissue. With US, echo intensity (EI) can be used to demonstrate changes caused by increased adipose tissue and intramuscular fibers. EI was defined as the average pixel intensity in the muscle and its value. EI can be measured by computer guided gray scale analysis using the standard histogram function in Adobe Photoshop program. Fat replacement and muscle atrophy make muscle tissue heterogeneous and hyper echoic and that cause increase in the EI. Therefore, muscle EI increases with denervated muscles [9]. High muscle echo intensity has been suggested as evidence of muscle changes due to neuropathy and myopathy [7].

The aim of this study is to evaluate the diagnostic value of ultrasound in detecting atrophy of foot muscles in diabetic peripheral neuropathy as compared to electrodiagnostic findings and to evaluate the correlation between quantitative muscle US findings and NCS results in patients with diabetic peripheral neuropathy (DPN).

\section{Material and Methods}

\section{Material:}

Twenty-five patients with peripheral neuropathy and 25 normal healthy volunteers were recruited from Physical Medicine, Rheumatology and Rehabilitation Department at National Institute of Neuro-
Motor System from July 2018 to April 2019 [matching in age, sex and body mass index (BMI)]. Patients were confirmed to have DPN by history, clinical examination with particular attention tolocomotor examination and electrodiagnostic study Patients with medical conditions that could cause peripheral neuropathy (PN) such as endocrine / metabolic causes (chronic renal failure, liver failure, hypothyroidism), drugs (amiodarone, isoniazide, colchicines, metronidazole, chemotherapy), peripheral vascular disease autoimmune disorders (SLE, RA, Sjogren syndrome), tumors (direct tumor infiltration, leukemia, lymphoma) or alcohol consumption were excluded.

All individuals included in this study were informed about the study design and consent was obtained.

\section{Methods:}

\section{Musculoskeletal Ultrasonography (MSK US):}

Transverse US images of the tibial-innervated abductor haullicis ( $\mathrm{AH}$ )muscle and the peronealinnervated extensor digitorum brevis (EDB) muscle were obtained to measure muscle cross-sectional area $(\mathrm{CSA})$ in $\left(\mathrm{mm}^{2}\right)$, thickness $(\mathrm{T})$ in $(\mathrm{mm})$, and EI on both sides. US was performed with the subject lying fully relaxed in a supine position with the ankle at neutral (i.e. $0^{\circ}$ ) as shown in (Fig.1).

For $\mathrm{AH}$ measurement, the probe was placed $1 \mathrm{~cm}$ proximal and $1 \mathrm{~cm}$ inferior to navicular prominence. EDB measurement was performed on dorsal lateral foot over the muscle belly just above the articulation between the calaneous and navicular as shown in (Fig. 1).

All patients were examined with commercially available equipment using a 7-18 MHZ Linear transducer (Aplio 400, Toshiba ultrasound Machine) in Fig. (2). The muscle T, CSA and EI were measured using B-mode US under the machine standards gain and depth presets for MSK scanning (gain $50 \mathrm{db} \& 2 \mathrm{~cm}$ depth). A visible US gel layer of 2$7 \mathrm{~mm}$ was maintained between the transducer and the skin on the ultrasound monitor for objective and consistent evaluation of the region of interest (ROI). The presence of a gel layer resulted in minimal compression from the transducer to the skin and the underlying tissues. Thickness (T) of the AH and EDB muscles was measured between the upper and lower margins of the muscles at the thickest part and was determined using a line selection tool to connect the dorsal most aspect of the muscle with the planter most aspect of the muscle. 

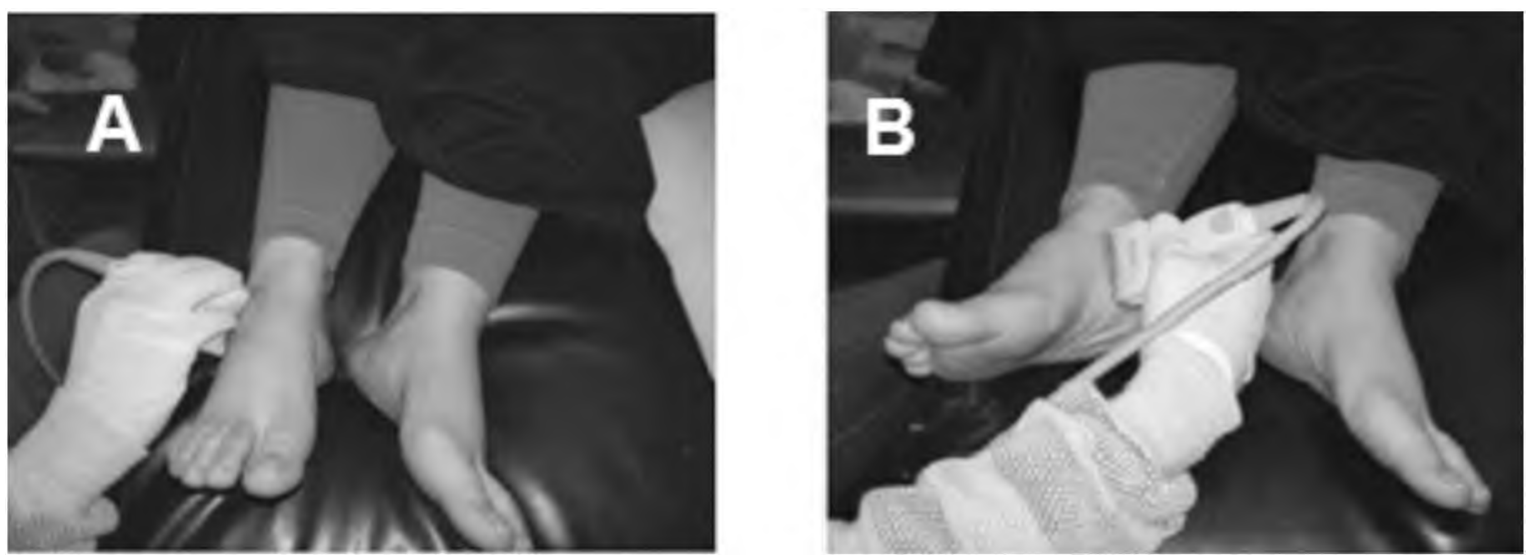

Fig. (1): Showing Position of the patient during ultrasonography examination with probe placing.

(A): Examination of (EDB) muscle. (B): Examination of (AH) muscle.

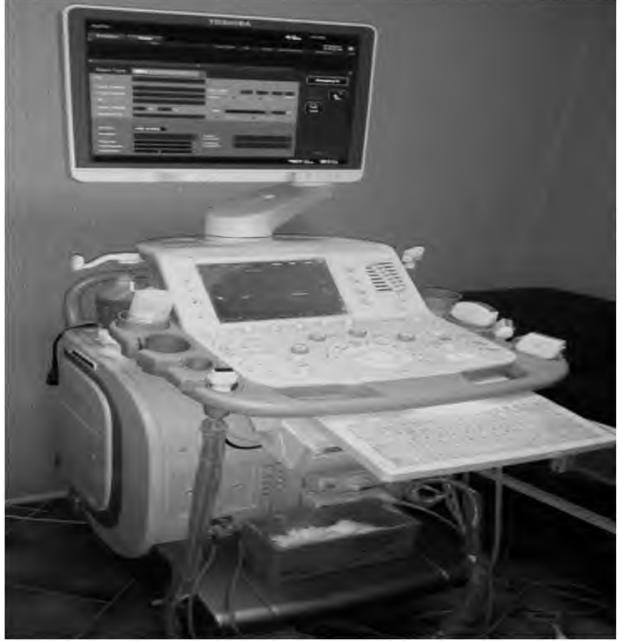

Fig. (2) Showing Aplio 400 US machine.

To measure the CSA, transverse images of the muscles were obtained at the level of maximum CSA. The CSA of the AH and EDB muscles were determined by outlining the muscle contour by the internal rim using the area measurement software of the US system (Fig. 3).

EI was determined using computer-assisted, grayscale analysis. ROIs were drawn for analysis

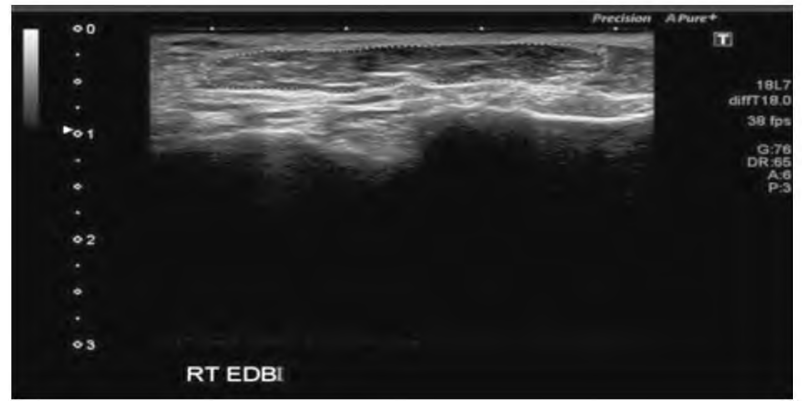

Fig. (3): Showing Outlining the muscle contour by the internal rim (region of interest ROI). of muscle EI using the line along the muscle fascia. Grayscale images were used to quantify muscle EI within each ROI. A grayscale image consists of achromatic color pixels with different brightness values ranging from 0 (pure black) to 255 (pure white) (Fig. 4). EI increase in denervated muscles due to fibrous and fat replacement which make muscle tissue heterogenous and hyperechoic as in (Fig. 5).

We analyzed muscle EI by using the standard histogram function of a graphics package (Adobe Photoshop CS6). The EI was measured in three images taken of each muscle. The subject was allowed to move, and the transducer was repositioned between each measurement. The mean of the three images was taken to reduce the variation.

\section{Electrodiagnostic study:}

All control and DPN subjects underwent a bilateral motor NCS of tibial and peroneal nerves using the Neuro-MEP $\omega$ Electrodiagnostic System (Fig. 6) to measure the amplitude of compound muscle action potential (CMAP), conduction velocity, latency and $\mathrm{F}$ wave (to exclude radiculopathy) with standard methods as described elsewhere (Preston \& David, 2013) as shown in (Fig. 7).

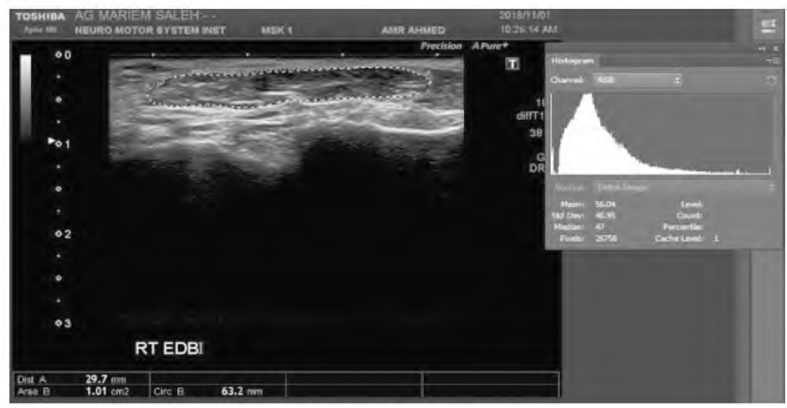

Fig. (4): Showing Muscle EI by using the standard histogram function of a graphics package (Adobe Photoshop CS6). 

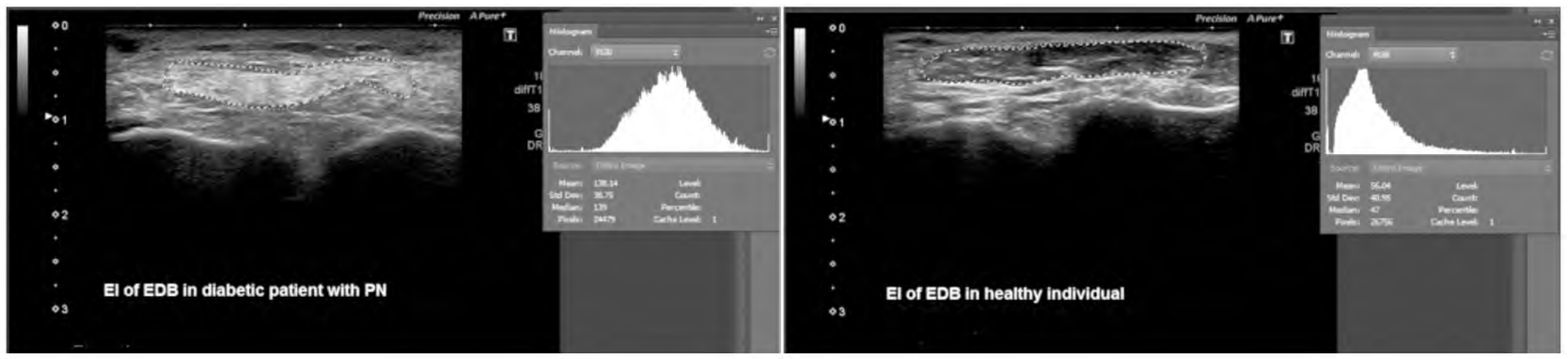

Fig. (5): Showing the difference in EI between DPN patients and healthy individuals.

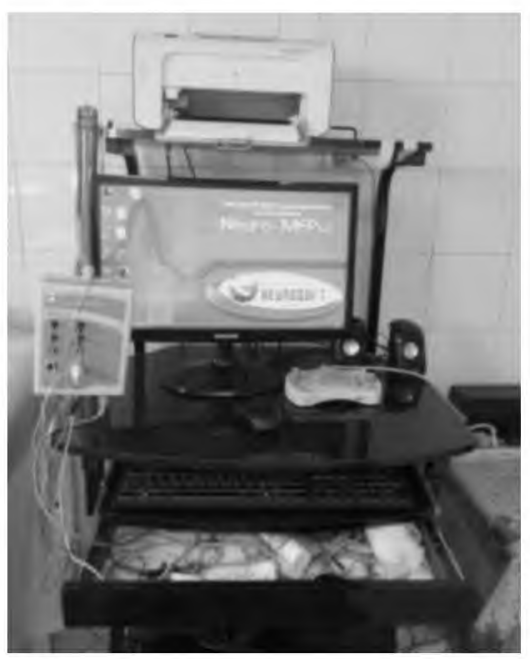

Fig. (6): Showing Neuro - MEP electrodiagnostic equipment (NEUROSOFT, Voronin str., Ivanovo, 153032, Russia).
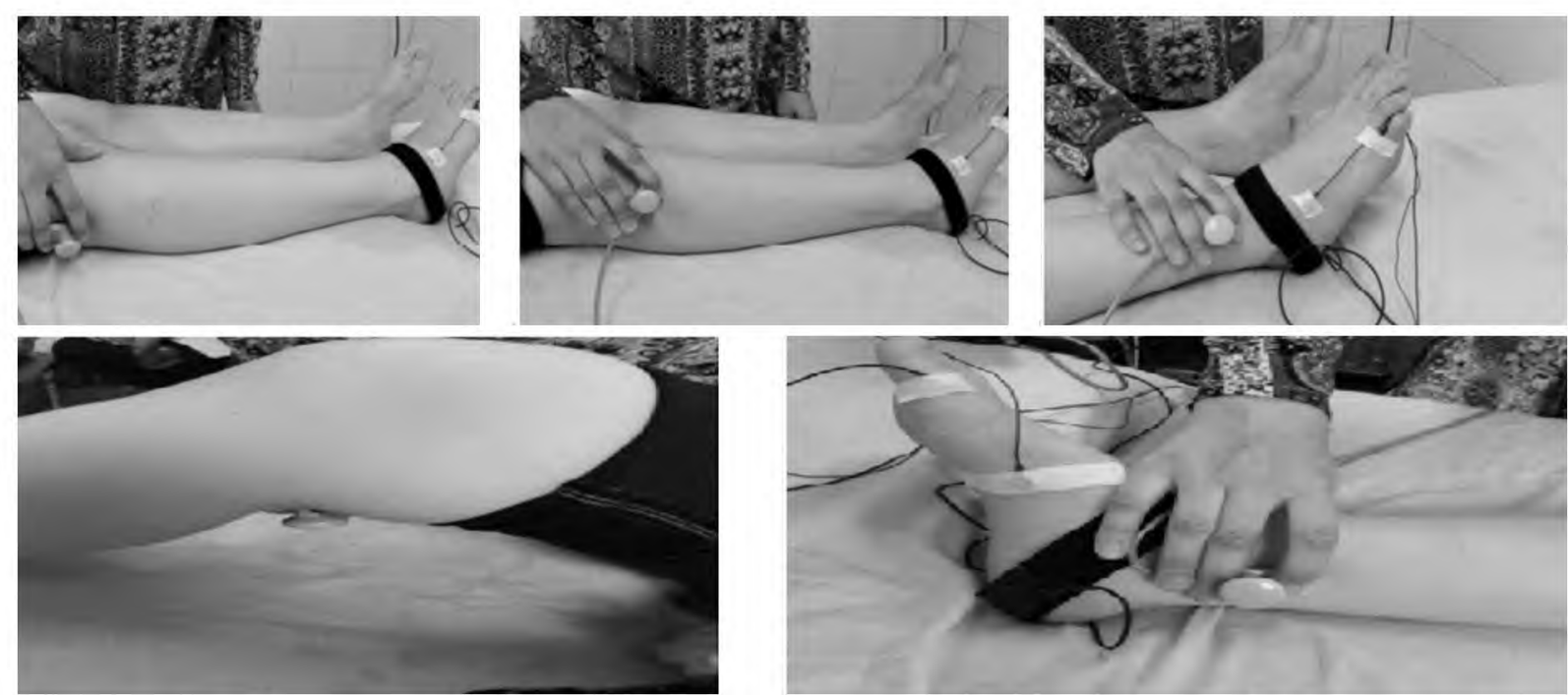

Fig. (7): Showing stimulation of peroneal and tibial nerves.

Patients group were subjected to additional laboratory investigations to exclude other causes of peripheral neuropathy. That will include:

- Complete Blood Count (CBC): Is done by electronic counting machine.

- Fasting Plasma Glucose, 2h Plasma Glucose and Glycosylated Hemoglobin (HB A1c).

- Erythrocytes Sedimentation Rate (ESR) in mm/ hr done by wintergreen technique.
- Liver and Kidney functions.

- Thyroid stimulating hormone (TSH).

\section{Statistical methods:}

Data were coded and entered using the statistical package SPSS version 25. Data was summarized using mean, standard deviation, median, minimum and maximum for quantitative variables and frequencies (number of cases) and relative frequencies (percentages)for categorical variables. 
Comparisons between groups were done using unpaired $t$-test in normally distributed quantitative variables while non-parametric Mann-Whitney test was used for non-normally distributed quantitative variables [11]. For comparing categorical data, Chi square $\left(\chi^{2}\right)$ test was performed. Exact test was used instead when the expected frequency is less than 5 [12]. Correlations between quantitative variables were done using Spearman correlation coefficient [13]. $p$-value $=$ Level of significance in all tests:

- If $p<0.001=$ Highly significant (HS).

- If $p<0.05=$ Significant (S).

- If $p>0.05=$ Non-significant (NS).

\section{Results}

This study was conducted on 25 patients with diabetic peripheral neuropathy. The baseline demographic data of study population is shown in Tables $(1,2)$.

Table (1\&2): Description of demographic data of patients and control groups.

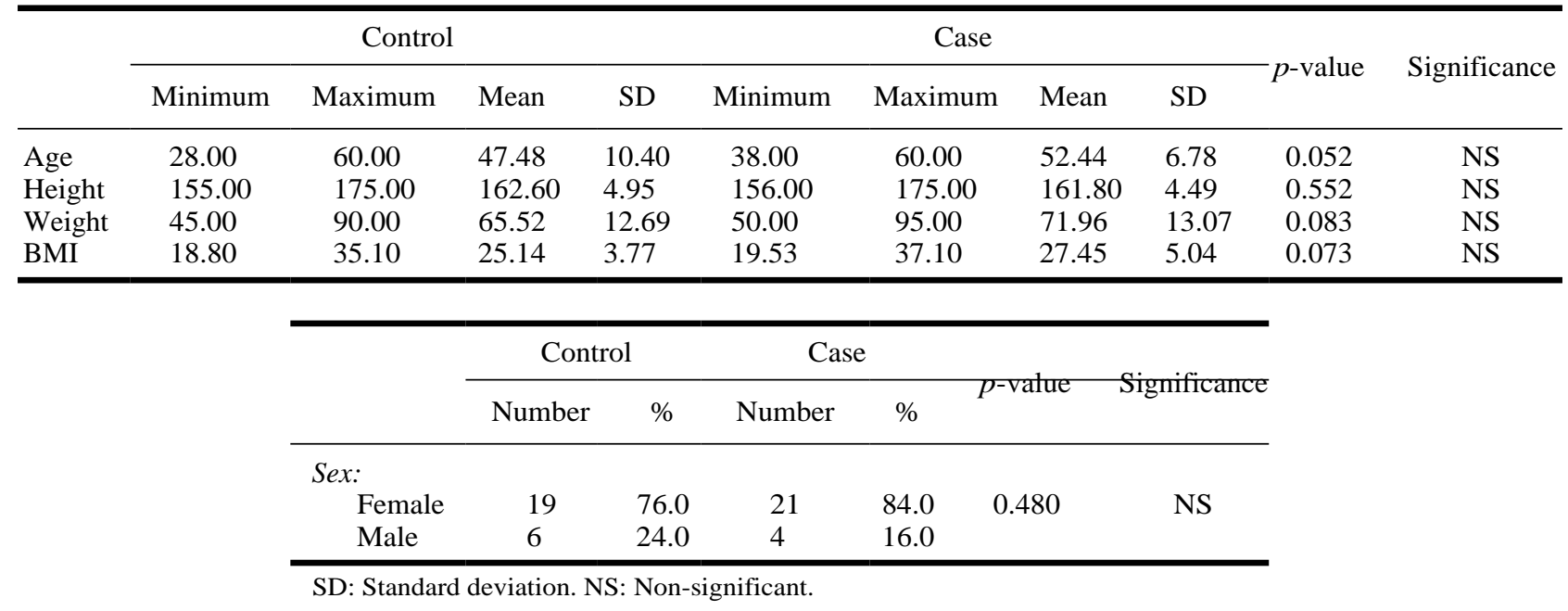

Ultrasound results among patient and control groups:

Echo Intensity (EI), muscle thickness (T) and cross sectional area (CSA) of abductor hallucis (AH) and extensor digitorum brevis (EDB) among the controls and cases are as shown in Table (3).
Comparison between cases and controls regarding quantitative US of $\mathrm{AH}$ and EDB muscles as regard EI,T and CSA, revealed a statistically insignificant difference in most the parameters $(p>$ 0.05 ) and some parameters showed statistically significant difference $(p<0.05)$ as shown in Table (3).

Table (3): Comparison between cases and control regarding quantitative US.

\begin{tabular}{|c|c|c|c|c|c|c|c|c|c|c|}
\hline & \multicolumn{4}{|c|}{ Control } & \multicolumn{4}{|c|}{ Case } & \multirow{2}{*}{$p$-value } & \multirow{2}{*}{ Significance } \\
\hline & Minimum & Maximum & Mean & SD & Minimum & Maximum & Mean & SD & & \\
\hline $\begin{array}{l}\text { RT EDB T } \\
(\mathrm{mm})\end{array}$ & 4.20 & 10.50 & 6.44 & 1.65 & 3.60 & 9.60 & 6.01 & 1.48 & 0.340 & NS \\
\hline $\begin{array}{l}\text { RT EDB CSA } \\
\left(\mathrm{cm}^{2}\right)\end{array}$ & 1.01 & 2.95 & 1.73 & 0.57 & 0.53 & 2.64 & 1.53 & 0.48 & 0.193 & NS \\
\hline RT EDB EI & 39.06 & 73.54 & 59.74 & 7.06 & 44.37 & 135.34 & 72.56 & 24.46 & 0.018 & $\mathrm{~S}$ \\
\hline RT AH T & 6.40 & 13.20 & 10.04 & 1.80 & 5.90 & 13.00 & 9.45 & 1.84 & 0.259 & NS \\
\hline RT AH CSA & 0.88 & 2.74 & 1.78 & 0.53 & 0.56 & 2.87 & 1.65 & 0.53 & 0.377 & NS \\
\hline RT AH EI & 18.83 & 55.20 & 36.01 & 9.14 & 21.03 & 77.72 & 42.99 & 14.82 & 0.051 & NS \\
\hline LT EDB T & 4.50 & 10.70 & 6.55 & 1.69 & 3.10 & 11.60 & 6.12 & 1.71 & 0.375 & NS \\
\hline LT EDB CSA & 0.88 & 2.83 & 1.64 & 0.54 & 0.62 & 3.02 & 1.57 & 0.49 & 0.630 & NS \\
\hline LT EDB EI & 41.77 & 73.42 & 57.35 & 7.75 & 39.56 & 117.34 & 64.40 & 19.01 & 0.096 & NS \\
\hline LT AH T & 6.80 & 12.40 & 9.46 & 1.56 & 4.30 & 11.10 & 8.29 & 1.88 & 0.020 & $\mathrm{~S}$ \\
\hline LT AH CSA & 0.96 & 2.63 & 1.79 & 0.56 & 0.54 & 2.36 & 1.37 & 0.48 & 0.006 & $\mathrm{~S}$ \\
\hline LT AH EI & 19.47 & 55.05 & 35.97 & 10.86 & 20.23 & 92.82 & 49.20 & 17.63 & 0.002 & $\mathrm{~S}$ \\
\hline $\begin{array}{l}\text { Echo Intenisty (E } \\
\text { Muscle thickness } \\
\text { Cross sectional a }\end{array}$ & (T) & $\begin{array}{l}\text { Abd } \\
\text { Exte } \\
\text { Rigl }\end{array}$ & $\begin{array}{l}\text { ctor hall } \\
\text { sor digi } \\
\text { (RT). }\end{array}$ & um bre & $\begin{array}{l}\mathrm{AH}) \\
(\mathrm{EDB})\end{array}$ & & $\begin{array}{l}\text { (LT). } \\
\text { imeter ( } \\
\text { timeter }\end{array}$ & & & \\
\hline
\end{tabular}


Correlation between quantitative ultrasound and electrodiagnostic findings in patients:

There was no significant correlation between quantitative US and electrodiagnostic parameters in the control group. However, correlation between US and NCS inside patients' group is significant in many items as shown in the following tables (Tables 4-15).

Correlation between RT Peroneal NCS and US findings in patients is shown in Tables $(4,5,6)$ :

Table (4): Correlation between RT peroneal distal amplitude and RT EDB thickness, CSA and EI.

\begin{tabular}{llll}
\hline & $\begin{array}{c}\text { RT EDB T } \\
(\mathrm{mm})\end{array}$ & $\begin{array}{c}\text { RT EDB CSA } \\
\left(\mathrm{cm}^{2}\right)\end{array}$ & RT EDB EI \\
\hline $\begin{array}{llll}\text { RT P D A: } \\
\text { Correlation }\end{array}$ & 0.545 & 0.585 & $-0.740-$ \\
$\begin{array}{l}\text { Coefficient } \\
p \text {-value }\end{array}$ & 0.006 & 0.003 & $<0.001$ \\
Significance & $\mathrm{S}$ & $\mathrm{S}$ & $\mathrm{S}$ \\
\hline
\end{tabular}

Table (5): Correlation between RT peroneal latency and RT EDB thickness CSA and EI.

\begin{tabular}{llll}
\hline & $\begin{array}{c}\text { RT EDB T } \\
(\mathrm{mm})\end{array}$ & $\begin{array}{c}\text { RT EDB CSA } \\
\left(\mathrm{cm}^{2}\right)\end{array}$ & RT EDB EI \\
\hline RT P D L: & & & \\
$\begin{array}{l}\text { Correlation } \\
\text { Coefficient }\end{array}$ & $-0.342-$ & $-0.200-$ & 0.225 \\
$\begin{array}{l}p \text {-value } \\
\text { Significance }\end{array}$ & 0.102 & 0.348 & 0.290 \\
& NS & NS & NS \\
\hline
\end{tabular}

Table (6): Correlation between RT peroneal velocity and RT EDB thickness, CSA and EI.

\begin{tabular}{|c|c|c|c|}
\hline & $\begin{array}{l}\text { RT EDB T } \\
(\mathrm{mm})\end{array}$ & $\begin{array}{c}\text { RT } \underset{\left(\mathrm{cm}^{2}\right)}{\mathrm{EDB}_{2} \mathrm{CSA}} \\
.\end{array}$ & RT EDB EI \\
\hline \multicolumn{4}{|l|}{$R T P V:$} \\
\hline $\begin{array}{l}\text { Correlation } \\
\text { Coefficient }\end{array}$ & 0.464 & 0.448 & $-0.656-$ \\
\hline$p$-value & 0.026 & 0.032 & 0.001 \\
\hline Significance & $\mathrm{S}$ & $\mathrm{S}$ & $\mathrm{S}$ \\
\hline
\end{tabular}

Correlation between LT Peroneal NCS and US findings in patients is shown in Tables $(7,8,9)$ :

Table (7): Correlation between LT peroneal amplitude and LT EDB CSA and EI

\begin{tabular}{|c|c|c|c|}
\hline & $\begin{array}{c}\mathrm{LT} \text { EDB T } \\
(\mathrm{mm})\end{array}$ & $\begin{array}{c}\mathrm{LT} \mathrm{EDB}{ }_{2} \mathrm{CSA} \\
\left(\mathrm{cm}^{2}\right)\end{array}$ & LT EDB EI \\
\hline \multicolumn{4}{|l|}{ LTPA: } \\
\hline $\begin{array}{l}\text { Correlation } \\
\text { Coefficient }\end{array}$ & 0.635 & 0.602 & 0.588 \\
\hline$p$-value & 0.001 & 0.002 & 0.003 \\
\hline Significance & $\mathrm{S}$ & $\mathrm{S}$ & $\mathrm{S}$ \\
\hline
\end{tabular}

Table (8): Correlation between LT peroneal latency and LT EDB thickness, CSA and EI.

\begin{tabular}{llll}
\hline & $\begin{array}{c}\text { LT EDB T } \\
(\mathrm{mm})\end{array}$ & $\begin{array}{c}\text { LT EDB CSA } \\
(\mathrm{cm})\end{array}$ & LT EDB EI \\
\hline $\begin{array}{l}\text { LT P L: } \\
\text { Correlation }\end{array}$ & 0.311 & $-0.454-$ & 0.422 \\
$\begin{array}{c}\text { Coefficient } \\
p \text {-value }\end{array}$ & 0.148 & 0.030 & 0.045 \\
Significance & $\mathrm{NS}$ & $\mathrm{S}$ & $\mathrm{S}$ \\
\hline
\end{tabular}

Table (9): Correlation between LT peroneal velocity and LT EDB thickness, CSA and EI.

\begin{tabular}{cccc}
\hline & $\begin{array}{c}\text { LT EDB T } \\
(\mathrm{mm})\end{array}$ & $\begin{array}{c}\text { LT EDB CSA } \\
\left(\mathrm{cm}^{2}\right)\end{array}$ & LT EDB EI \\
\hline \hline$L T P V:$ & & & \\
Correlation & 0.432 & 0.443 & 0.324 \\
Coefficient & & & \\
$p$-value & 0.0 .040 & 0.034 & 0132 \\
Significance & $\mathrm{S}$ & $\mathrm{S}$ & $\mathrm{NS}$ \\
\hline
\end{tabular}

Correlation between RT Tibial NCS and US findings in patients is shown in Tables $(10,11,12)$ :

Table (10): Correlation between RT Tibial amplitude and RT AH thickness, CSA and EI.

\begin{tabular}{|c|c|c|c|}
\hline & $\begin{array}{c}\text { RT AH T } \\
(\mathrm{mm})\end{array}$ & $\begin{array}{c}\mathrm{RT} \underset{\left(\mathrm{cm}_{2}\right)}{\mathrm{AH}_{2} \mathrm{CSA}} \\
\end{array}$ & RT AH EI \\
\hline \multicolumn{4}{|l|}{$R T T A:$} \\
\hline $\begin{array}{l}\text { Correlation } \\
\text { Coefficient }\end{array}$ & 0.256 & 0.213 & $-0.494-$ \\
\hline$p$-value & 0.217 & 0.306 & 0.012 \\
\hline Significance & NS & NS & S \\
\hline
\end{tabular}

Table (11): Correlation between RT Tibial latency and RT AH thickness, CSA and EI.

\begin{tabular}{llll}
\hline & $\begin{array}{c}\mathrm{RT} \mathrm{AH} \mathrm{T} \\
(\mathrm{mm})\end{array}$ & $\begin{array}{c}\mathrm{RT} \mathrm{AH}_{2} \mathrm{CSA} \\
\left(\mathrm{cm}^{2}\right)\end{array}$ & RT AH EI \\
\hline$R T T L:$ & & & \\
$\quad \begin{array}{l}\text { Correlation } \\
\text { Coefficient }\end{array}$ & 0.135 & 0.054 & $-0.495-$ \\
$\begin{array}{l}p \text {-value } \\
\text { Significance }\end{array}$ & 0.521 & 0.829 & 0.012 \\
\hline
\end{tabular}

Table (12): Correlation between RT Tibial velovity and RT AH thickness, CSA and EI.

\begin{tabular}{llll}
\hline & $\begin{array}{c}\text { RT AH T } \\
(\mathrm{mm})\end{array}$ & $\begin{array}{c}\mathrm{RT} \mathrm{AH}_{2} \mathrm{CSA} \\
\left(\mathrm{cm}^{2}\right)\end{array}$ & RT AH EI \\
\hline$R T T V:$ & & & \\
$\quad$ Correlation & 0.157 & 0.007 & $-0.351-$ \\
$\begin{array}{c}\text { Coefficient } \\
p \text {-value }\end{array}$ & 0.452 & 0.975 & 0.086 \\
Significance & $\mathrm{NS}$ & $\mathrm{NS}$ & $\mathrm{N}$ \\
\hline
\end{tabular}


Correlation between LT Tibial NCS and US findings in patients is shown in Tables $(13,14,15)$ :

Table (13): Correlation between LT Tibial amplitude and LT AH thickness, CSA and EI.

\begin{tabular}{llll}
\hline & $\begin{array}{c}\text { RT AH T } \\
(\mathrm{mm})\end{array}$ & $\begin{array}{c}\mathrm{RT} \mathrm{AH}_{2} \mathrm{CSA} \\
\left(\mathrm{cm}^{2}\right)\end{array}$ & RT AH EI \\
\hline $\begin{array}{c}\text { LT T A: } \\
\text { Correlation } \\
\text { Coefficient }\end{array}$ & 0.268 & 0.304 & $-0.390-$ \\
$\begin{array}{c}\text { p-value } \\
\text { Significance }\end{array}$ & 0.195 & 0.139 & 0.054 \\
\hline
\end{tabular}

Table (14): Correlation between LT Tibial velocity and LT AH thickness, CSA and EI.

\begin{tabular}{llll}
\hline & $\begin{array}{c}\mathrm{RT} \mathrm{AH} \mathrm{T} \\
(\mathrm{mm})\end{array}$ & $\begin{array}{c}\mathrm{RT} \mathrm{AH}_{2} \mathrm{CSA} \\
\left(\mathrm{cm}^{2}\right)\end{array}$ & RT AH EI \\
\hline $\begin{array}{c}\text { LT T L: } \\
\text { Correlation }\end{array}$ & 0.465 & 0.383 & $-0.470-$ \\
$\begin{array}{l}\text { Coefficient } \\
p \text {-value }\end{array}$ & 0.019 & 0.059 & 0.018 \\
Significance & $\mathrm{S}$ & $\mathrm{NS}$ & $\mathrm{S}$ \\
\hline
\end{tabular}

Table (15): Correlation between LT Tibial velocity and LT AH thickness, CSA and EI.

\begin{tabular}{llll}
\hline & $\begin{array}{c}\text { RT AH T } \\
(\mathrm{mm})\end{array}$ & $\begin{array}{c}\mathrm{RT} \mathrm{AH}_{2} \mathrm{CSA} \\
\left(\mathrm{cm}^{2}\right)\end{array}$ & RT AH EI \\
\hline $\begin{array}{c}\text { LT } T \text { : }: \\
\text { Correlation } \\
\text { Coefficient }\end{array}$ & 0.542 & 0.468 & $-0.392-$ \\
$\begin{array}{l}\text { p-value } \\
\text { Significance }\end{array}$ & 0.005 & 0.018 & 0.053 \\
\hline
\end{tabular}

\section{Discussion}

The aim of this study is to evaluate the diagnostic value of ultrasound in detecting atrophy of foot muscles in diabetic peripheral neuropathy as compared to electrodiagnostic findings and to evaluate the correlation between quantitative muscle US findings and NCS results in patients with diabetic peripheral neuropathy (DPN).

Electrodiagnostic study is the gold standard for evaluating muscle denervation in peripheral neuropathy [3]. In DPN amplitude and NCV are widely used to monitor the lesion. The amplitude of the CMAP (compound motor action potential) is suggested to be more relevant than NCV because it more closely represents axonal loss and thereby represents the functional effects of neuropathy such as loss of sensation and muscle weakness [14].
Progression in technology has led up to the wide use of Musculoskeletal US in many specializations. Differentiation of normal and abnormal anatomical structures is one of its main indications.

Amplitude of the US wave corresponds to the brightness of the image and the time between sending and receiving the US pulse determines the location of the corresponding pixel. The gray value of the image is determined by the amount of returning echoes per square unit area and that gray value is EI. Muscle EI was determined as mean pixel brightness. Accumulation of fat and fibrous tissue and denervation edema after nerve injury cause changes in muscle echogenicity [9].

In our results, the correlation observed between US findings (EI, CSA and muscle thickness) and NCS neuro-physiological findings was significant in many items indicating that we can use both examinations to detect muscle atrophy and that US can expect changes in neurophysiologic parameters in diabetics.

In patients with very small CMAPs amplitude (below $1 \mathrm{mV}$ ) and even in patients without a recordable amplitude a reduced amount of contractile muscle tissue could be detected by US.

This could be because of embedding of few dispersed muscle fibers in fatty and fibrous tissue. In severely atrophic muscles, CMAP may underestimate the amount of contractile tissue and ultrasound may overestimate the muscle size. This could be reduced in the future with US guided placement of needle electrodes in the remaining contractile muscle fibers enabling accurate recordings of the neurophysiological response.

In a study by Bargfrede et al., 1999 [15] similar findings were found. Their aim was to evaluate the diagnostic value of muscle US in focal neuropathies. Findings showed that US was as sensitive as EMG in detecting muscle affection. Musculoskeletal ultrasound and EMG were complementary. Increased (EI) was seen in $82 \%$, atrophy in $31 \%$ of affected muscles. Muscle US can visualize anatomical abnormalities in lesions of nerve roots, plexus, and peripheral nerve lesions. Their study suggested US as a complementary method in the evaluation not only of generalized neuromuscular diseases, but also in injuries of nerve roots, plexus, and single peripheral nerves.

We found that the findings in the peroneal nerve were more significant than those in tibial nerve. 
That is because our study showed that the correlations between NCS parameters (amplitude, latency and the nerve conduction velocity of the peroneal and the tibial nerve) and US parameters (EI, thickness and CSA of small muscles of the foot) were significant in many items. The Correlation between RT Peroneal NCS and US findings in patients showed significant correlation between (distal amplitude and NCV) and (EI, CSA and muscle thickness). Correlation between LT Peroneal NCS and US findings in patients showed significant correlation between (distal amplitude) and (EI, CSA and muscle thickness), (latency) and (EI and CSA) and between (NCV) and (muscle thickness and CSA). Correlation between RT Tibial NCS and US findings in patients showed significant correlation between (distal amplitude and latency) and (EI). Correlation between LT Tibial NCS and US findings in patients showed significant correlation between latency and (EI and muscle thickness) and between NCV and (muscle thickness and CSA).

For peroneal nerve, the amplitude reflected the atrophy of the EDB muscle more than the nerve conduction velocity and latency.

These results come in accordance with Severinsen et al., 2007 [16] who examined 26 diabetic patients with and without various degrees of neuropathy, complaining or not complaining of motor deficits or symptoms. In their study the CSA of (EDB) and of the muscles between the first and second metatarsal bone (including (1) The adductor hallucis muscle, (2) The first lumbrical muscle and (3) The first interosseus dorsalis muscle) was determined. Motor NCS of the tibial and peroneal nerves were performed with detection of the amplitudes of the CMAPs and of the (NCV).

They concluded that the main result of their study was that the amplitude of the CMAP and the $\mathrm{NCV}$ of the tibial and the peroneal nerve are closely related to the CSA of small muscles of the foot detected by ultrasound.

In our study we found that there was a clinical importance of the US EI more than the CSA. However, in contrary to our study, the cross-sectional area of EDB was suggested as the most sensitive parameter especially for screening in massive population in a study by Wang et al., 2014 [17].

They demonstrated US detection of foot muscle atrophy in 106 Chinese diabetic patients of type 2 DM with or without DPN (56 males, 50 females, mean age of $61 \pm 6$ years, range of 38-78 years). Some of their results was similar to our results as they demonstrated that foot muscle atrophy occurred in diabetic patients (including those without DPN) could be detected by high frequency MSK US. That difference is probably due to conducting their study on a larger number of patients with variable subjects' characteristics.

In the present study comparison between cases and controls regarding quantitative ultrasound of $\mathrm{AH}$ and EDB muscles as regard EI,T and CSA, revealed a statistically insignificant difference in most the parameters and some parameters showed statistically significant difference (RT EDB EI, LT AH EI, LT AH CSA, LT AH Thickness). However, there was a clinical importance of the US examination (especially for the EI) despite the insignificant statistics. This is most likely because of the sample size is not large enough to detect a difference between groups. In addition, the impact of age and sex on EI was not assessed because the sample size is not large enough to allow a precise statistical analysis. Further study is needed to assess the effect of subject characteristics on echo intensity.

These findings are almost in line with those of Lee et al., 2016 [18], who made a study on 20 patients with carpal tunnel syndrome (CTS) and 20 healthy volunteers.

Median and ulnar (NCS) and quantitative muscle US were done bilaterally in patients and controls. US images of the abductor digiti minimi (ADM) and the abductor pollicis brevis (APB) were obtained to measure muscle (EI), (CSA) and thickness. US findings of CTS patients significantly differed from those of the control group. EI of the APB muscle correlated with the NCS findings of CTS. Muscle thickness and CSA were significantly decreased, and EI was significantly increased in the APB of the CTS group. These findings suggest that Quantitative analysis of muscle thickness, CSA, and EI could be a more objective and reliable method to detect (PN) peripheral neuropathy. Comparison of muscle US parameters between CTS patients and controls showed that the muscle thickness and CSA of the APB were significantly decreased in CTS patients, and EI of the APB was significantly increased in CTS patients. However, results of ADM measurements did not differ significantly between controls and patients. These findings suggest that Quantitative analysis of muscle thickness, CSA, and EI could be a more objective and reliable method to detect (PN).

In a study with 150 children Pillen et al., 2007 [19] found that skeletal muscle US can be a non- 
invasive valuable method in the diagnosis of neuromuscular lesions in children. Discrimination between children with and without a neuromuscular disorder with high predictive values, in a short time and with minimal discomfort became possible by US. Quantification of EI enabled comparing changes in different muscles, describing the distribution of pathology throughout the body and distinguishing neurogenic disorders from myopathic disorders with a positive predictive value of $86 \%$ and a negative predictive value of $84 \%$. Neurogenic lesions showed more changes (increased EI and atrophy) in the legs, while myopathy showed a more equal distribution of EI and muscle thickness within the body.

The present study had some limitations. First, the number of subjects was not large enough. Additionally, we couldn't test the ability of MSK US to detect the early muscle affection as the patients group was already suffering from the effect of DPN (the risk of developing symptomatic PN in patients even without neuropathic symptoms or signs by the time of the diagnosis of DM is estimated to be about $4 \%$ to $10 \%$ by 5 years [2].

We have only one experienced US examiner, so we couldn't assess the inter-rater reliability of quantitative US (that needs two examiners to conduct US examinations in each subject on the same day).

Therefore, it is not appropriate to generalize the results to all DPN patients. Further studies with larger sample size of early diabetics examined by two US examiners are necessary to increase the understanding of the clinical value and applicability of this method.

We also did not use the US to assess the CSA of the nerves. More studies are needed to detect the role of US in demonstrating the relationship between the CSA of the nerves and the muscle changes in DPN.

In conclusion, correlation between US and NCS inside patient group is significant in many items. The amplitude of the CMAP assessed by motor NCS closely reflects the EI and size of small muscles of the foot as determined by ultrasound. Thus, standard motor NCS provide information about muscle atrophy in DPN.

However, US may detect existing muscle in patients with small or unrecordable CMAP, suggesting that this technique may add more information in patients with severe neuropathy and sever muscle atrophy.
Quantitative US analysis of muscle EI, thickness and CSA could be a more objective and reliable method to detect (PN). Therefore, quantitative muscle US may be clinically helpful in determining the presence of DPN. However, further studies are needed to confirm the findings in larger groups of diabetic patients and to evaluate peripheral muscles by using quantitative muscle US in other types of neuropathy and neuromuscular diseases.

\section{Recommendation:}

- We recommend the routine use of NCS as a standard test in confirming the clinical diagnosis of DPN up till now.

- Further studies are needed to detect the role of US in detecting the muscle changes in DPN. We suggest using a larger sample size including controls and pre or early diabetic swithout DPN in addition to diabetics with DPN symptoms to assess the US value in detecting the very early muscle changes and for better assessment of the value of EI in relation to variable subjects' characteristics.

- The use of US guided placement of needle electrodes in the remaining contractile muscle fibers will enable more accurate recordings of the neurophysiological response.

- We also recommend that the individuals should be examined by two US examiners to detect the intra-rater reliability for increasing the understanding of the clinical value and applicability of this method.

- Furthermore, we suggest to study the relationship between the CSA of the nerves and the muscle changes in DPN both detected by US.

\section{References}

1- SINGH R., KISHORE L. and KAUR N.: Diabetic peripheral neuropathy: Current perspective and future directions. Pharmacol. Res., 80: 21-35, 2014.

2- BASHAR KATIRJI: Bradley's Neurology in Clinical Practice, $7^{\text {th }}$ edition, 107: 1791-1866.e12, 2016.

3- WERNER R.A. and ANDARY M.: Electrodiagnostic evaluation of carpal tunnel syndrome. Muscle Nerve, 44: 597-607, 2011.

4- RUBIN D.I.: Technical issues and potential complications of nerve conduction studies and needle electromyography. Neurol. Clin., 30: 685-710, 2012.

5- KOENIG R.W., PEDRO M.T., HEINEN C.P., SCHMIDT T., RICHTER H.P., ANTONIADIS G., et al: Highresolution ultrasonography in evaluating peripheral nerve entrapment and trauma. Neurosurg Focus, 26: E13, 2009.

6- GELLHORN A.C. and CARLSON M.J.: Inter-rater, intrarater, and inter-machine reliability of quantitative ultrasound measurements of the patellar tendon. Ultrasound Med. Biol., 39: 791-6, 2013. 
7- MAURITS N.M., BOLLEN A.E., WINDHAUSEN A., De JAGER A.E. and VAN DER HOEVEN J.H.: Muscle ultrasound analysis: Normal values and differentiation between myopathies and neuropathies. Ultrasound Med. Biol., 29: 215-25, 2003.

8- HYEWON LEE, SUNGJUJEE, SOOHO PARK, SEUNGCHAN AHN, JUNEHOIM and MIN KYUNSOHN: Quantitative Muscle Ultrasonography in Carpal Tunnel Syndrome. Ann. Rehabil Med., 40 (6): 1048-1056, 2016.

9- ARTS I.M., PILLEN S., SCHELHAAS H.J., OVEREEM S., ZWARTS M.J.: Normal values for quantitative muscle ultrasonography in adults. Muscle Nerve, 41: 32-41, 2010.

10- PRESTON D.C. and SHAPIRO B.E.: Electromyography and Neuromuscular Disorders E-Book: ClinicalElectrophysiologic Correlations (Expert Consult-Online and Print). Elsevier Health Sciences, 2012.

11- CHAN Y.H.: Biostatistics 102: Quantitative Data - Parametric \& Non-parametric Tests. Singapore Med. J., 44 (8): 391-396, 2003a.

12- CHAN Y.H.: Biostatistics 103: Qualitative Data -Tests of Independence. Singapore Med. J., 44 (10): 498-503, 2003 b.

13- CHAN Y.H.: Biostatistics 104: Correlational Analysis. Singapore Med. J., 44 (12): 614-619, 2003c.

14- DYCK P.J., DAVIES J.L., LITCHY W.J. and O'BRIEN
P.C.: Longitudinal assessment of diabetic polyneuropathy using a composite score in the Rochester Diabetic Neuropathy Study cohort. Neurology, 49: 229-39, 1997.

15- BARGFREDE M., SCHWENNICKE A., TUMANI H. and REIMERS C.D.: Quantitative ultrasonography in focal neuropathies as compared to clinical and EMG findings. European Journal of Ultrasound, 10 (1): 21-29, 1999.

16- SEVERINSEN K. and ANDERSEN H.: Evaluation of atrophy of foot muscles in diabetic neuropathy-a comparative study of nerve conduction studies and ultrasonography. Clinical Neurophysiology, 118 (10): 2172-2175, 2007.

17- WANG X., CHEN L., LIU W., SU B. and ZHANG Y.: Early detection of atrophy of foot muscles in Chinese patients of type 2 diabetes mellitus by high-frequency ultrasonography. Journal of Diabetes Research, 2014.

18- LEE H., JEE S., PARK S.H., AHN S.C., IM J. and SOHN M.K.: Quantitative muscle ultrasonography in carpal tunnel syndrome. Annals of Rehabilitation Medicine, 40 (6): 1048, 2016.

19- PILLEN S., VERRIPS A., VAN ALFEN N., ARTS I.M.P., SIE L.T.L. and ZWARTS M.J.: Quantitative skeletal muscle ultrasound: diagnostic value in childhood neuromuscular disease. Neuromuscular Disorders, 17 (7): 509-516, 2007.

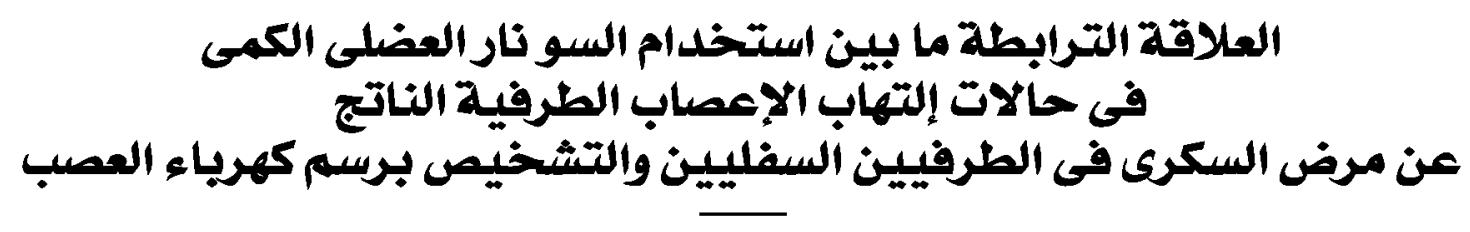

الهدف من هذه الدراسة: هو تقييم دود الموجات فوق الصوتية الكمية في تثخيص نمط الاعتلال العصبي في اعتلال الأعصاب الطرفية

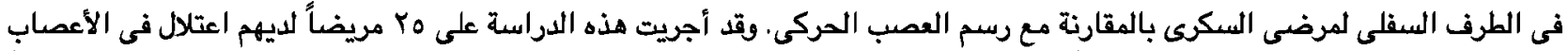

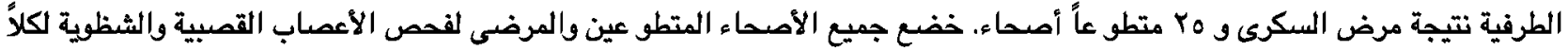

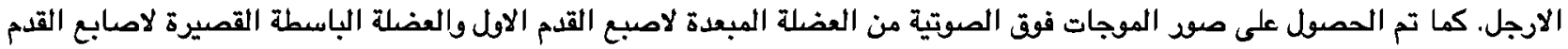
على كلا الناحيتين. لقياس سمك العضلات ومساحة مقطعها وكثافة الصدى. تم تصديد شدة المدىى باستخدام تمليل تدرج الرمادى بمساعدة الكمبيوتر.

في هذه الدراسة، لوحظ وجود علاقات وثيقة بين نتائج السونار (كثافة الصدى ومساحة المقطع العضلى ويسمك العضلات) والنتائج العصبية

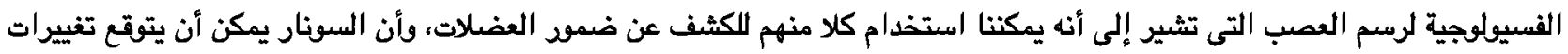

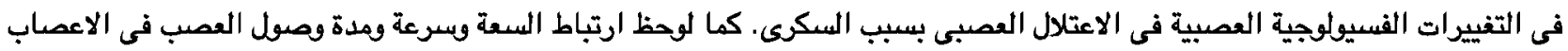

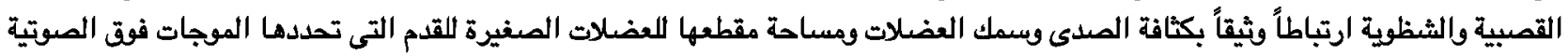

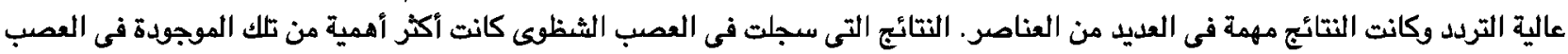

القصبى. بالنسبة إلى العصب الشظىى، تعكس السعى CMAP ضمور العضلة الباسطة القصيرة أكثر من سرعة توصيل العصب NCV.

كثفت المقارنة بين الصالات والضوابط فيما يتعلق بالموجات فوق الصوتية الكمية لعضلات الباسطة والمباعدة لاصابع القدم فيما يتعلق

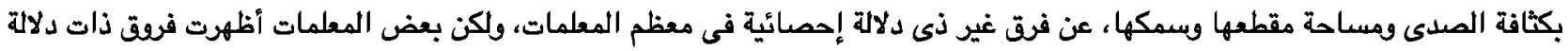

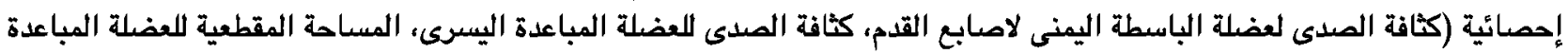

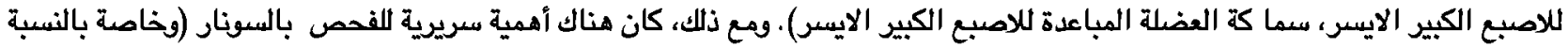

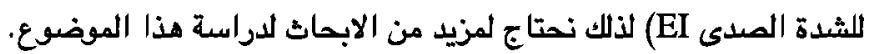

